\title{
Lung cavitation associated with Pneumocystis carinii infection in the acquired immunodeficiency syndrome: a report of six cases and review of the literature
}

\author{
C. Ferré*, F. Báguena**, D. Podzamczer*, C. Sánchez**, \\ P.F. Viladrich*, J. Garau**, F. Gudiol*
}

Lung cavitation associated with Pneumocystis carinii infection in the acquired immunodeficiency syndrome: a report of six cases and review of the literature. C. Ferré, F. Báguena, D. Podzamczer, C. Sánchez, P.F. Viladrich, J. Garau, F. Gudiol. CERS Journals Ltd 1994.

ABSTRACT: Lung cavitation in patients with the acquired immune deficiency syndrome (AIDS) and Pneumocystis carinii pneumonia (PCP) has mainly been reported as single case studies. Among 160 episodes of PCP seen in a 1,000 bed teaching hospital and a 600 bed teaching hospital from 1985-1992, we found six cases presenting with lung cavitation and documented Pneumocystis carinii infection. In the cases we report, as well as in the cases reviewed, cavities appear either alone or within an area of pulmonary consolidation, a mass or a nodule. They may present with haemoptysis, show unusual locations and, most importantly, may frequently be misdiagnosed by bronchoalveolar lavage.

Eur Respir J., 1994, 7, 134-139.
*Infectious Diseases Service, Hospital de Bellvitge, Universitat de Barcelona, Barcelona, Spain. **Dept of Internal Medicine, Hospital Mútua de Terrassa, Universitat de Barcelona, Terrassa (Barcelona), Spain.

Correspondence: C. Ferré

Hospital de Bellvitge

Servei de Malalties Infeccioses

c/Feixa Llarga s/n

L'Hospitalet de Llobregat

08907 Spain

Keywords: Acquired immunodeficiency syndrome; bronchoalveolar lavage; lung cavitation; Pneumocystis carinii.

Received: September 161992

Accepted after revision July 201993
Among patients with acquired immune deficiency syndrome (AIDS), Pneumocystis carinii (PCP) is the most common pulmonary opportunistic infection, and is estimated to occur in approximately $60-80 \%$ of patients [1]. Its radiographic features, both in AIDS and non-AIDS patients, are typically described as a bilateral interstitial or alveolar pattern. Unusual and atypical roentgenographic manifestations include unilateral distribution, focal infiltrates, lobar involvement, atelectatic changes, cystic or honeycomb lesions, nodular densities, hilar enlargement, spontaneous pneumothorax, unilateral hyperlucent lung, pleural effusion, and lungs appearing roentgenographically clear in up to $5 \%$ of cases [2-12]. Lung cavitation is an unusual presentation of PCP, of which mainly single case reports have been published. In these cases, cavitation appears to develop in a nodule or mass, to be surrounded by, or to accompany, diffuse lung disease or consolidation, or manifest radiographically as single or multiple cavities, which in some cases are presumed to be abscesses [13-28].

\section{Patients and methods}

The records of six patients with PCP, radiographically presenting with cavitary lesions, were reviewed. These patients were seen at the Hospital de Bellvitge and the Hospital Mútua de Terrassa (a 1,000 bed and a 600 bed teaching hospital, respectively, in the Barcelona area) during the period from March 1985 to May 1992. During that time, 160 episodes of documented PCP were observed, $63 \%$ being the first AIDS-defining condition with a median of 24 cases per year (range 6-38). In our series, $66 \%$ of patients with PCP had intravenous drug abuse as a risk factor for AIDS, $22 \%$ were homosexual, $10 \%$ heterosexual and $2 \%$ were in other groups. Whenever induced sputum was negative, bronchoalveolar lavage (BAL) was performed, using a fibreoptic bronchoscope (Olympus BF type 20). The tip of the bronchoscope was wedged in a subsegmental bronchus, chosen on the basis of the roentgenographic findings. Bronchial wash specimens $(20-30 \mathrm{ml})$ were obtained, after washing with $50-100 \mathrm{ml}$ of saline solution. Staining methods included Gomori's methenamine silver and Giemsa.

In addition, all cases of cavitary forms of PCP reported in the literature were reviewed. Since a variety of cystic pulmonary lesions have been described in patients with AIDS and Pneumocystis carinii infection, we tried to include only those cases with cavities according to the definition given by the Nomenclature Committee of the Fleischner Society: "a lucency within a zone of pulmonary consolidation, a mass, or a nodule; hence, a lucent area within the lung that may or may not contain a fluid level and that is surrounded by a wall, usually of varied thickness" [29]. We have not included those cases cited only in PCP series but not clearly described. 


\section{Case reports}

\section{Case A}

A 28 year old ex-drug addict was admitted to hospital because of fever, chest pain, and cough, with occasional haemoptysis. X-ray films of the chest showed a cavitary lesion with a fluid level in the right upper lobe (fig. 1). CD4 count was $65 \cdot \mathrm{mm}^{-3}$. Stains and cultures from a BAL specimen were negative and amoxycillin/clavulanic was empirically instituted, with no improvement. A transthoracic needle aspiration (TNA) was performed, but cultures were negative. A pneumothorax subsequently developed, fever reappeared, and two days later a diffuse alveolar-interstitial pattern was seen in the left upper lobe. A second bronchoscopy was performed, and smears of the BAL stained with Gormori's methenamine silver revealed Pneumocystis carinii. Two months later, the lesions had almost disappeared (fig. 2), and the patient was later lost to follow-up.

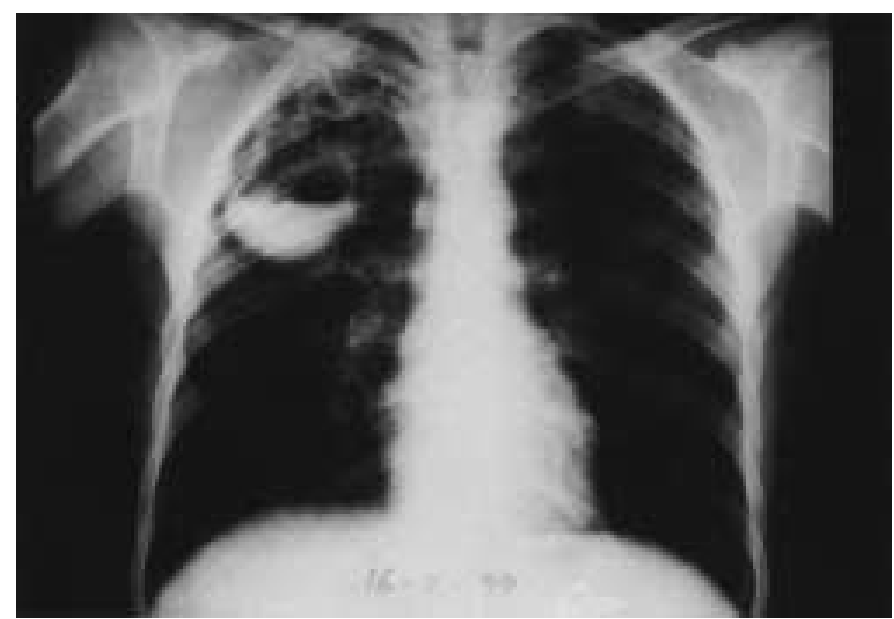

Fig. 1. - Case A: a multiloculated cavitary lesion with a fluid level in the right upper lobe.

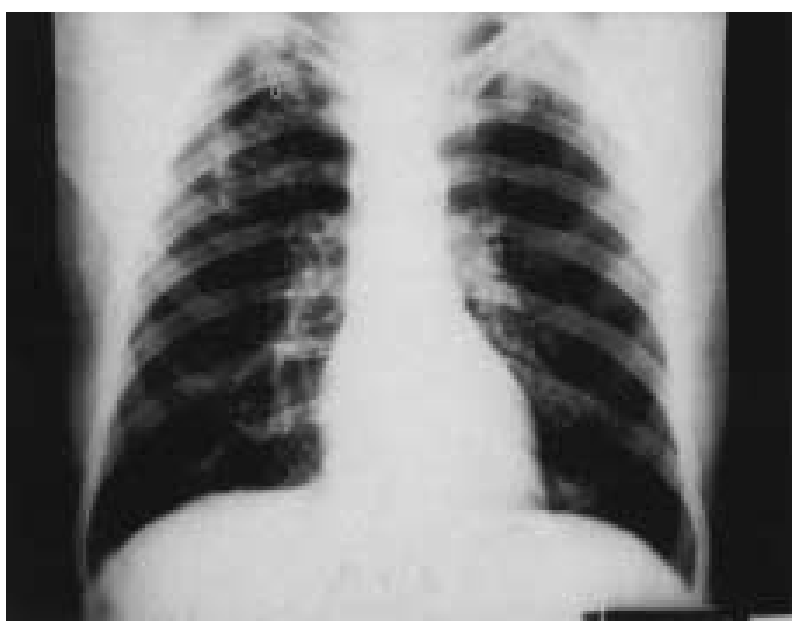

Fig. 2. - Case A: two months after discharge the chest roentgenogram shows almost complete resolution.

\section{Case B}

A 34 year old ex-drug addict was admitted, presenting with a cavity in the left upper lobe. CD4 count was $100 \cdot \mathrm{mm}^{-3}$. Smears and cultures from sputum and BAL were negative. Culture from a TNA sample revealed Haemophilus influenzae and Streptococcus pneumoniae and a 6 week amoxycillin/clavulanic regimen was instituted. Chest X-ray remained unchanged, and a further bronchoscopy was carried out. Culture from a sample obtained through a protected catheter brush yielded Haemophilus influenzae (40,000 colony forming units (cfu)). Thoracotomy was undertaken, with total excision of the lesion. Pathological findings revealed an interstitial lymphoplasmocytic infiltrate, and necrotizing granulomatous process, with intra-alveolar foamy exudates. The Gomori's methenamine silver stain revealed the presence of encysted forms of Pneumocystis carinii.

\section{Case $C$}

A 31 year old man was admitted to the hospital because of fever and haemoptysis. A chest X-ray disclosed a $2 \times 2 \mathrm{~cm}$ cavity in the left lower lobe. CD4 count was $6 \cdot \mathrm{mm}^{-3}$. Pseudomonas aeruginosa grew in several sputum sample. A fibreoptic bronchoscopy was performed, and bronchoalveolar lavage yielded Pneumocystis carinii and no other micro-organisms. The patient was treated with co-trimoxazole at usual doses. One month after discharge, the cavity remained unchanged and the patient was once again admitted because of severe haemoptysis. A selective arteriography with embolization was necessary to control bleeding. Pseudomonas aeruginosa grew once again from a protected catheter brush specimen. The patient died 6 months later after several bouts of fever, dyspnoea and cough, with persistent Pseudomonas aeruginosa infection. At that time a $2 \times 2 \mathrm{~cm}$ cavity was still visible.

\section{Case D}

A 29 year old homosexual and active drug addict was admitted to the hospital because of fever and malaise. One year previously he had had an episode of PCP, and thereafter had refused to follow any prophylactic regimen. Four months previously he had received chemotherapy for cutaneous and visceral Kaposi's sarcoma. One week before admission the patient experienced the onset of fever, cough and mild dyspnoea. A chest X-ray showed a $2.5 \times 2 \mathrm{~cm}$ cavity, within an area of infiltrate, in the right middle lobe. CD4 count was $20 \cdot \mathrm{mm}^{-3}$. BAL yielded Pneumocystis carinii. Eight months later the patient died of sepsis due to Pseudomonas aeruginosa of urinary origin. In the left lower lobe, a cavity of the same size with a thin wall was visible.

\section{Case E}

A 27 year old active drug addict was admitted to the hospital because of fever, cough with a mucopurulent sputum, and chest pain. He was being treated with zidovudine 


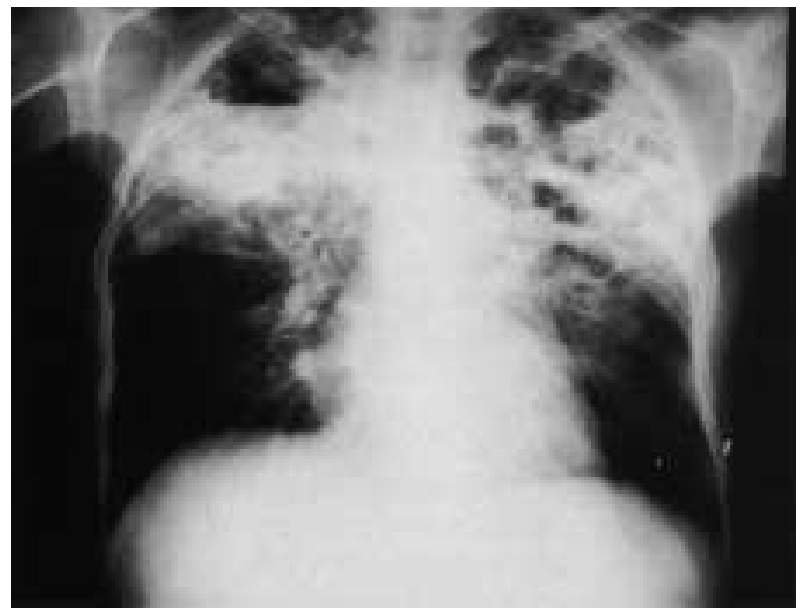

Fig. 3. - Case E: areas of consolidation in both upper lobes, with multiloculated cavities and a fluid level.

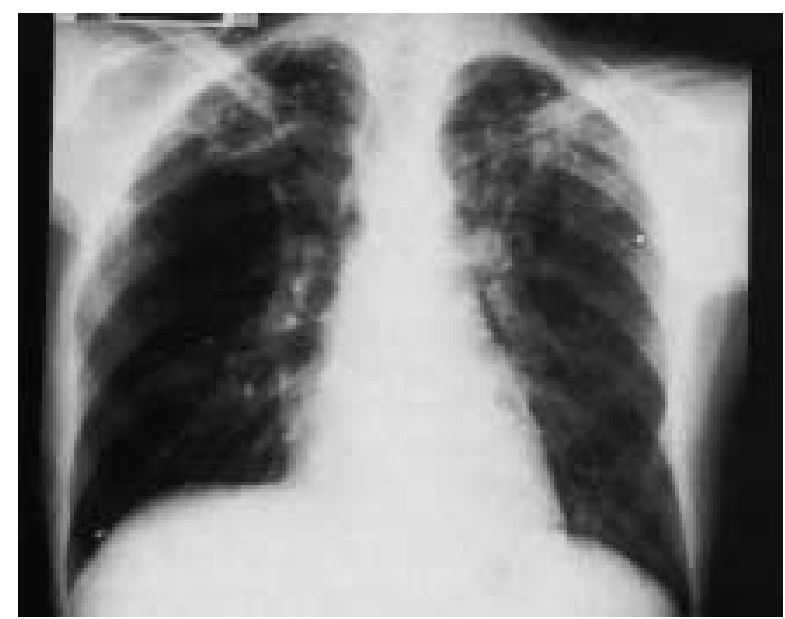

Fig. 4. - Case E: chest roentgenogram two months later showing clear improvement.

and prophylactic aerosolized pentamidine $\left(4 \mathrm{mg} \cdot \mathrm{kg}^{-1}\right.$ once a week). CD4 count was $190 \cdot \mathrm{mm}^{-3}$. An X-ray showed consolidating lesions in both upper lobes and in the lingula, with multiloculated cavities (fig. 3). Streptococcus pneumoniae grew from blood cultures, but no radiological improvement was seen with cefuroxime. TNA and BAL were nondiagnostic. An open lung biopsy yielded Pneumocystis carinii. Co-trimoxazole was instituted with clinical and radiological improvement (fig. 4).

\section{Case F}

A 32 year old homosexual was admitted to the hospital because of intermittent fever and cough of two months duration. A chest X-ray showed a single cavity in the left upper lobe, surrounded by an interstitial infiltrate, and a similar infiltrate, in the right upper lobe with no gas-containing spaces. CD4 count was $74 \cdot \mathrm{mm}^{-3}$. A fibreoptic bronchoscopy was performed and repeated, but specimens from BAL, and transbronchial biopsy (TBB) at the second procedure, were negative for stains and

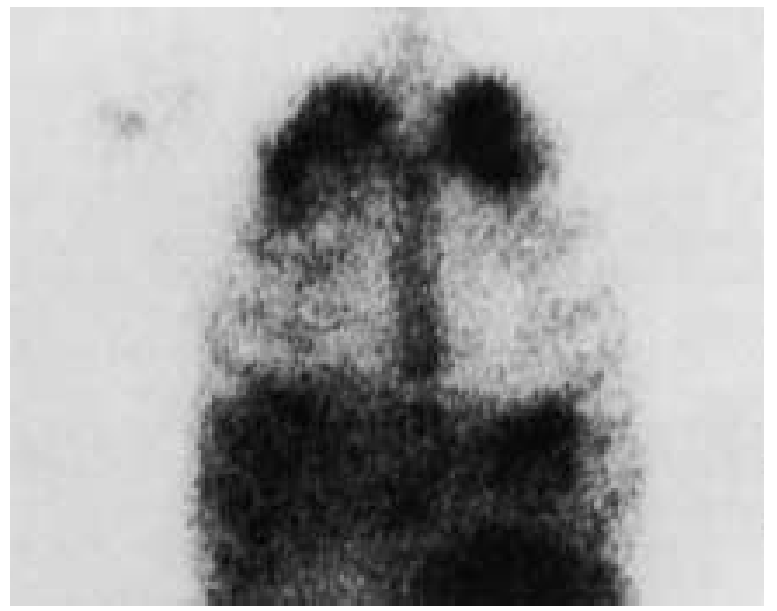

Fig. 5. - Case F: gallium-67 citrate scan shows an intense and focal uptake in both upper lobes.

culture. A gallium-67 citrate scan showed intense focal uptake in both apical zones (fig. 5). An open lung biopsy was performed; a granulomatous reaction at the periphery, and central fibrosis with foci of necrosis containing Pneumocystis carinii organisms was observed. Some days later a pneumothorax developed which required drainage. Nine months later, a chest X-ray was normal.

\section{Discussion}

Since 1984, 29 cases of PCP with cavitary lesions (including our own) have been reported in the English, French and Spanish literature. All cases are summarized in table 1.

Only five of the cases had received prophylaxis with aerosolized pentamidine, but none with co-trimoxazole. In addition to the usual clinical findings of PCP, haemoptysis was found at presentation in some cases. From a radiological point of view, lesions tend to be intraparenchymal, and the unusual location in the upper lobes in 21 of the 29 cases reviewed is noteworthy.

Since the onset of the AIDS epidemic, many reports have dealt with the different cystic lesions (bullae, blebs, pneumatoceles or cavities) that may be found in PCP, although many of these lesions were also described before AIDS [30]. The major theories [4, 15, 23, 31-34] regarding the pathogenesis of these cystic lesions include: 1) alveolar-interstitial pneumonitis leading to cyst-like structures, probably due to elastinolytic proteases liberated by activated macrophages; 2 ) ischaemic necrosis due to invasion of the vascular lumina by Pneumocystis carinii; 3) concomitant or prior episodes of pulmonary infections; and 4) barotrauma as an additional factor in patients under mechanical ventilation.

However, clinical and morphological evidence of pulmonary destruction in AIDS may appear with no concurrent infection. Smoking, intravenous drug abuse and, in particular, prior and repeated infections (most often prior episodes of PCP) have been implicated in the appearance of premature bullous damage $[35,36]$. Moreover, 


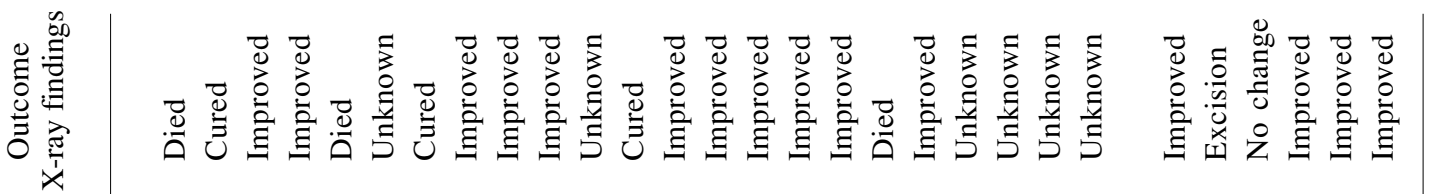

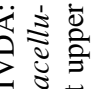

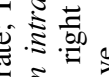

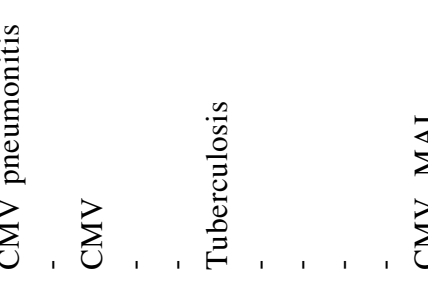

$\stackrel{+}{\oplus} \stackrel{+}{\mathcal{a}}$

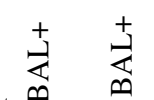

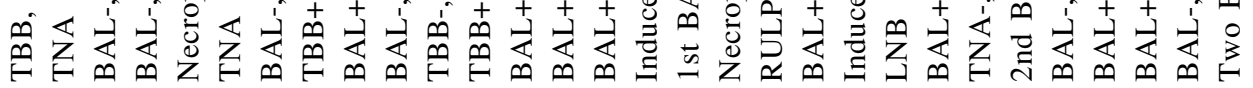

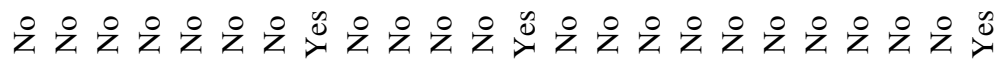
운운

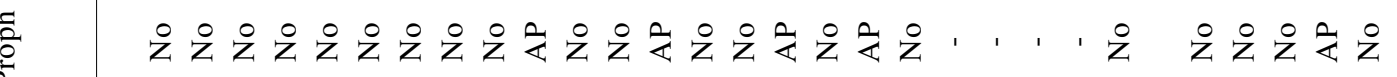

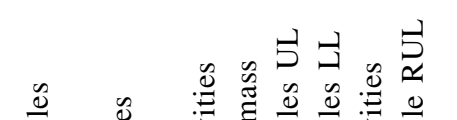

\&

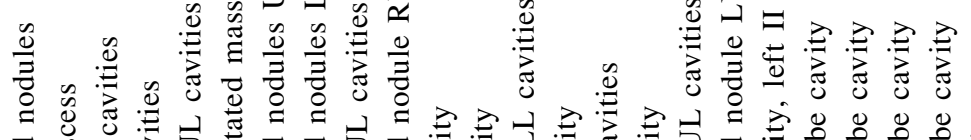

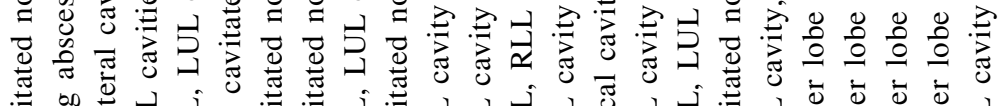

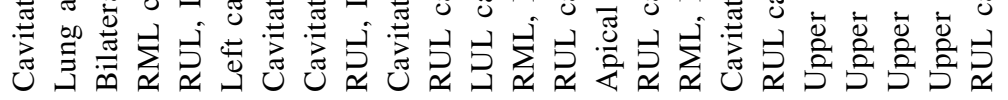

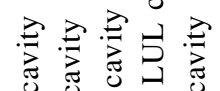
$\stackrel{\substack{0 \\:}}{\stackrel{0}{0}}$

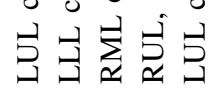

$$
\Sigma
$$

$\underset{8}{\infty}$

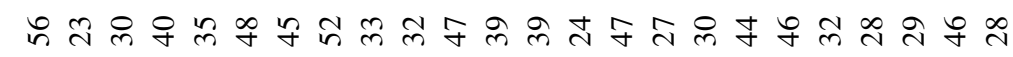

竞

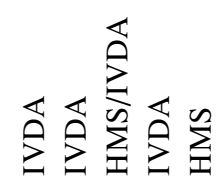

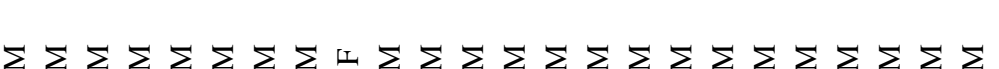

$\Sigma \Sigma \Sigma \Sigma \Sigma$

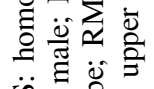

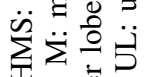

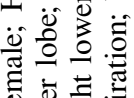

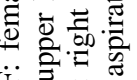

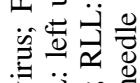
ة्் 西 공응 $\ddot{z} \cong$ 泀艺 离总氞忌 空芒 要遂 थิ ชิ

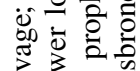
츠을 형웜에 芒蓞 可 형으월

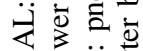
唫离 完苛焉 高

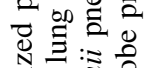
勻过 这䒺 安究 نे 颌 范 过 
in laboratory studies, human immunodeficiency virus (HIV) infection itself has been proven to have a direct cytotoxic effect on lung macrophages, that may liberate proteases and lyse insoluble elastin fibrils [37]. Taking into account all the above-mentioned arguments, it would seem that gas-containing spaces in the setting of AIDS and PCP may have a multifactorial origin.

All of our patients were smokers, but rather too young to show extensive emphysematous changes, and all but one were current or past intravenous drug users. We cannot be sure how this might have contributed to the clinical and radiological appearance, but in the biopsies performed there was no intravascular foreign material mixed with thrombi. Bacterial infection was found in three of the six patients. These concomitant infections may certainly have played a role in cavity formation. Nevertheless, the appearance of Pneumocystis carinii in the lung biopsies, and the response to anti-pneumocystis therapy leads us to suggest that this organism is a direct cause or contributor of cavitation.

The appearance of a granulomatous reaction in two of our patients (cases No. B and F) is noteworthy. PCP seems to be rarely associated with granulomatous inflammation. TRAVIS et al. [33] found six cases with granulomas, among 123 lung biopsies from 76 patients, and single cases have been reported [26, 38-40]. The granulomatous response probably tends to occur in nodularappearing PCP and, although not proven, it is suggested that these patients might retain some degree of immunoresponsiveness.

In four patients (cases No. 8, 13, 24 (A) and 29 (F)), a pneumothorax was reported. In cases No. 24 (A) and $29(\mathrm{~F})$, the pneumothorax appeared shortly after invasive procedures were performed. In case No. 8, a moderate degree of pneumothorax developed adjacent to an area of cavitated nodular opacities in the right lower lobe, in the setting of PCP with a 3 month history. In case No. 13 , a 39 year old man with three previous episodes of PCP, who subsequently received prophylaxis with aerosolized pentamidine, presented with cavitary lesions in the right middle and lower lobe, together with a pneumothorax requiring drainage. We believe that pneumothorax should be regarded as a potential complication in PCP with cavitary lesions. BEERs et al. [41] have shown that in certain patients Pneumocystis carinii infection induces significant tissue destruction, with resultant bullae formation or cavitation, and subsequent spontaneous rupture leading to pneumothorax.

Suprisingly, among the $21 \mathrm{BAL}$ procedures reported in the cases reviewed, including our own, only 11 yielded Pneumocystis carinii. This high incidence of falsenegative results is a notable fact. Cavities arising in a nodule, lack of alveolar-interstitial infiltrates, or appearance in the upper lobes, may contribute to such results. This situation may have important implications in the management of these patients. Whether or not TBB may be more sensitive than BAL in cavitary forms of PCP is unknown. From 10 TBB in the 29 cases reviewed, four were negative (cases No. 3, 4, 11 and 29 (F)), and when both diagnostic components of bronchoscopy (BAL and TBB) were performed (cases No. 3, 4, 7, 10, 20 and 29
(F)) BAL was negative in five cases and TBB in three. Obviously, there are not enough cases to make definite conclusions, but in an HIV-infected patient with cavitary lesions, it seems reasonable to perform both BAL and TBB in an attempt to improve the overall diagnostic accuracy before an open lung biopsy is indicated.

In conclusion, PCP in AIDS may present with a great variability of cystic lesions, probably from a multifactorial origin. In the case of cavities, concomitant infections should, in particular, be considered. Patients frequently show lesions located in the upper lobes. Bronchoalveolar lavage, a highly specific and sensitive diagnostic procedure in "classic" PCP, often fails to reveal the presence of Pneumocystis carinii. It is probably worth performing both TBB and BAL in an attempt to improve the overall diagnostic accuracy.

\section{References}

1. Glatt AE, Chirgwin K. - Pneumocystis carinii pneumonia in human immunodeficiency virus-infected patient. Arch Intern Med 1990; 150: 271-279.

2. Gamsu G, Hecht ST, Birnberg FA, Coleman DL, Golden JA. - Pneumocystis carinii pneumonia in homosexual men. AJR 1982; 139: 647-651.

3. Milligan SA, Stulbarg MS, Gamsu G, Golden JA. Pneumocystis carinii pneumonia radiographically simulating tuberculosis. Am Rev Respir Dis 1985; 132: 1124-1126.

4. DeLorenzo LJ, Huang CT, Maguire GP, Stone DJ. Roentgenographic patterns of Pneumocystis carinii pneumonia in 104 patients with AIDS. Chest 1987; 91: 323-327.

5. Golden JA, Sollito RA. - The radiology of pulmonary disease. Chest radiography, computed tomography and gallium scanning. Clin Chest Med 1988; 9: 481-495.

6. Molthrop DC, Thiele JS, Cook EW, Faust BF. - Unusual Pneumocystis carinii pneumonia in an AIDS patient. $J$ Louisiana State Medic Soc 1987; 139: 63-65.

7. Groskin SA, Massi AF, Randall PA. - Calcified hilar and mediastinal lymph nodes in an AIDS patient with Pneumocystis carinii infection. Radiology 1990; 175: 345-346.

8. Shin MS, Liendo C, Ho KJ. - Pneumocystis carinii pneumonia in an AIDS patient. Unusual manifestation as multiple cavitary and noncavitary peripheral pulmonary nodules and spontaneous pneumothorax. Clin Imaging 1989; 13: 225-227.

9. Stokes DC, Shenep JL, Horowitz ME, Hughes WT. Presentation of Pneumocystis carinii pneumonia as unilateral hyperlucent lung. Chest 1988; 94: 201-202.

10. Goodman JL, Tashkin DP. - Pneumocystis with normal chest X-ray film and arterial oxygen tension. Early diagnosis in a patient with the acquired immune deficiency syndrome. Arch Intern Med 1983; 143: 1981-1982.

11. Smith DE, Wyatt J, McLuckie A, Gazzard B. - Severe exercise hypoxaemia with normal or near normal X-rays: a feature of Pneumocystis carinii infection. Lancet 1988; ii: $1049-1051$.

12. Barrio JL, Suarez M, Rodriguez JL, Saldana MJ, Pitchenik AE. - Pneumocystis carinii pneumonia presenting as cavitating and noncavitating nodules in patients with the acquired immunodeficiency syndrome. Am Rev Respir Dis 1986; 134:1094-1096.

13. Gagliardi AJ, Stover DE, Zaman MK. - Endobronchial 
Pneumocystis carinii infection in a patient with the acquired immune deficiency syndrome. Chest 1987; 91: 463-464.

14. Eng RH, Bishburg E, Smith SM. - Evidence for destruction of lung tissues during Pneumocystis carinii infection. Arch Intern Med 1987; 147: 746-749.

15. Liu YC, Tomashefsky JF, Tomford W, Green H. Necrotizing Pneumocystis carinii vasculitis associated with lung necrosis and cavitation in a patient with acquired immunodeficiency syndrome. Arch Pathol Lab Med 1989; 113: 494-497.

16. Cacuob P, Carette MF, Parquin F, et al. - Pneumocystoses excavantes au cours du SIDA: un nouvel aspect sémiologique. Ann Med Interne 1990; 141: 171-174.

17. De los Santos S, Capote F, Leal M, Verano A, Lissen E. - Primer caso de síndrome de inmunodeficiencia adquirida en un drogadicto de Sevilla (letter). Med Clin (Barc) 1986; 86: 129.

18. Pincus PS, Sandler MA, Naude GE, Kallenbach, Isaacson C, Zwi S. - Multiple pulmonary cavities: an unusual complication of Pneumocystis carinii pneumonia. S Afr Med J 1987; 72: 871-872.

19. Conetta R, Kilstein S, Chitkara RK. - Cavitation as an unusual roentgenographic manifestation of Pneumocystis carinii pneumonia in a patient with acquired immunodeficiency syndrome. NY State J Med 1988; 88: 652-653.

20. Conetta R, Chitkara RK. - Resolution of cavitary Pneumocystis carinii pneumonia (letter). NY State J Med 1990; 90: 162.

21. Fortun J, Antela A, Rey J, Montilla P. - Recidiva de Pneumocystis carinii tras el uso de pentamidina inhalada profiláctica. Hallazgos radiológicos poco habituales (letter). Med Clin (Barc) 1991; 96: 678.

22. Febvre M, De Fenoyl O, Capron F, Rochemaure J. Pneumopathie à Pneumocystis carinii: présentation atypique pseudotubérculouse. Rev Med Interne 1988; 9: 85-88.

23. Scully RE, Mark EJ, McNeely WF, McNeely BU. Case records of the Massachusetts General Hospital (Case 9-1989). N Engl J Med 1989; 320: 582-587.

24. Chechani V, Zaman MK, Finch PJ. - Chronic cavitary Pneumocystis carinii pneumonia in a patient with AIDS. Chest 1989; 95: 1347-1348.

25. Praz JO, Lorenzi P, Chevrolet JC. - Pneumocystis carinii pneumonia and acquired immunodeficiency syndrome: an atypical presentation with lung cavitations. Eur Respir J 1990; 3: 1221-1223.

26. Klein JS, Warnock M, Webb WR, Gamsu G. - Cavitating and noncavitating granulomas in AIDS patients with Pneumocystis pneumonitis. AJR 1989; 152: 753-754.
27. Cacoub P, Parquin F, Roux P, Carette MF, Mayaud C, Akoun G. - Un nouveau cas de pneumocystose nécrosante au cours du SIDA? Rev Pneumol Clin 1989; 45: 130-133.

28. Feuerstein IM, Archer A, Pluda JM, et al. - Thin-walled cavities, cysts, and pneumothorax in Pneumocystis carinii pneumonia: further observations with histopathologic correlation. Radiology 1990; 174: 697-702.

29. Tuddenham WJ. - Glossary of terms for thoracic radiology: recommendations of the Nomenclature Committee of the Fleischner Society. AJR 1984; 143: 509-517.

30. Doppman JL, Geehoeld GW, De Vita VT. - Atypical radiographic features in Pneumocystis carinii pneumonia. Radiology 1975; 114: 39-44.

31. Werb Z, Gordon S. - Elastase secretion by stimulated macrophages. Characterization and regulation. J Exp Med 1975; 142: 361-377.

32. Saldana MJ, Mones JM. - Cavitation and other atypical manifestations of Pneumocystis carinii pneumonia. Semin Diag Pathol 1989; 6: 273-286.

33. Travis WD, Pittaluga S, Lipschik GY, et al. - Atypical pathologic manifestations of Pneumocystis carinii pneumonia in the acquired immune deficiency syndrome. $A m$ J Surg Pathol 1990; 14(7): 615-625.

34. Kuhlman JE, Kavuru M, Fishman EK, Siegelman SS. Pneumocystis carinii pneumonia. Spectrum of parenchymal CT findings. Radiology 1990; 175: 711-714.

35. O'Donnell AE, Pappas LS. - Pulmonary complications of intravenous drug abuse. Chest 1988; 94(2): 251-253.

36. Kuhlman JE, Knowles MC, Fishman EK, Siegelman SS. - Premature bullous pulmonary damage in AIDS: CT diagnosis. Radiology 1989; 173: 23-26.

37. Salahuddin SZ, Rose RM, Groopman JE, Markham PD, Gallo R. - Human T-lymphotropic virus type III infection of human alveolar macrophages. Blood 1986; 68: 281-284.

38. Bhatt M, Muller M, Sabatini M. - Solitary pulmonary granulomatous pneumocystosis (letter). Ann Intern Med 1988; 109: 343-344.

39. Bleiweiss IJ, Jagirdar JS, Klein MJ, et al. - Granulomatous Pneumocystis carinii pneumonia in three patients with the acquired immunodeficiency syndrome. Chest 1988; 94: 580-583.

40. Blumenfeld W, Basgoz N, Owen WF, Schmidt DM. Granulomatous pulmonary lesions in patients with AIDS and Pneumocystis carinii infection. Ann Intern Med 1988; 109: 505-507.

41. Beers MF, Sohn M, Swartz M. - Recurrent pneumothorax in AIDS patients with Pneumocystis pneumonia. Chest 1990; 98: 266-270. 